\title{
Políticas educativas de fortalecimiento del liderazgo directivo: desafíos para Chile en un análisis comparado con países OCDE
}

Víctor Cancino Cancino a Leonardo Vera Monrroy ${ }^{b}$

\section{Resumo}

En la última década, para muchos países la dirección escolar y el liderazgo educativo se han convertido en prioridad para la política pública. Diversos factores explican la importancia asignada a esta función, destacándose: mayores expectativas de las familias sobre la educación; demandas de rendición de cuentas por los resultados educativos; nuevas tendencias en la provisión de servicios; y la evidencia de investigaciones sobre la influencia que ejerce la calidad de los procesos de dirección y liderazgo en la efectividad escolar. La Organización para la Cooperación y el Desarrollo Económico (OCDE) destaca la importancia del liderazgo educativo, analizando su estado actual y tendencias en países miembros, e identificando factores clave para su desarrollo. El artículo compara las políticas más recientemente aplicadas en Chile en este ámbito, contrastándolas con experiencias de los países OCDE, en función de lo cual se sugieren propuestas para un diseño de política pública sustentable en el marco señalado.

Palabras clave: Dirección escolar. Liderazgo educacional. Políticas de gestión escolar.

\section{Introducción}

Investigaciones recientes evidencian la existencia de una fuerte relación entre el liderazgo directivo de calidad en una escuela y el logro de resultados de aprendizajes de sus estudiantes (LEITHWOOD et al. 2006; ELMORE, 2010; WEINSTEIN; MUÑOZ, 2012), aun cuando se reconoce que este efecto es de carácter indirecto, ya que se vincula a factores que potencian la capacidad de obtener aprendizajes,

\footnotetext{
a Universidad Santo Tomás, Talca, Chile.

b Universidad de Playa Ancha, Programa de Doctorado en Política y Gestión Educativa, Chile. 
como son la motivación docente, el desarrollo de sus capacidades y sus condiciones laborales, y en la medida que esto ocurre son ellos quienes afectan el aprendizaje de los estudiantes a través de mejores prácticas de enseñanza.

Un estudio realizado a directores de escuelas públicas en Estados Unidos (WALLACE FOUNDATION, 2005), cuya característica común eran sus buenos resultados progresivos a diferencia de escuelas similares, entrega evidencia del impacto total (directo/indirecto) que el liderazgo generó, estimándolo en cerca de un $25 \%$ del total del efecto escuela sobre el logro de los aprendizajes. El hallazgo más importante del estudio es que un buen liderazgo es más importante mientras más problemas o circunstancias difíciles experimenta una escuela, es decir, sus alcances son más notorios mientras más necesidades de mejoramiento existan.

Intentando precisar los dominios o dimensiones del actuar de los directivos que producen estos efectos, en el colectivo de docentes y a nivel individual, Leithwood et al. (2007), señalan que los directores influencian a los profesores motivándolos, armonizando su compromiso y mejorando sus condiciones laborales; de esta manera, afectan indirectamente la enseñanza y aprendizaje de los estudiantes, tal como se muestra en la Figura 1.

Si observamos cada una de las "sendas" de influencia del liderazgo propuestas por los autores, y las contrastamos con información de investigaciones que se han efectuado a nivel nacional e internacional respecto a materias similares, es posible distinguir elementos específicos de las actuaciones de los líderes vinculados a cada una, a saber: la influencia vinculada al desarrollo de capacidades docentes;
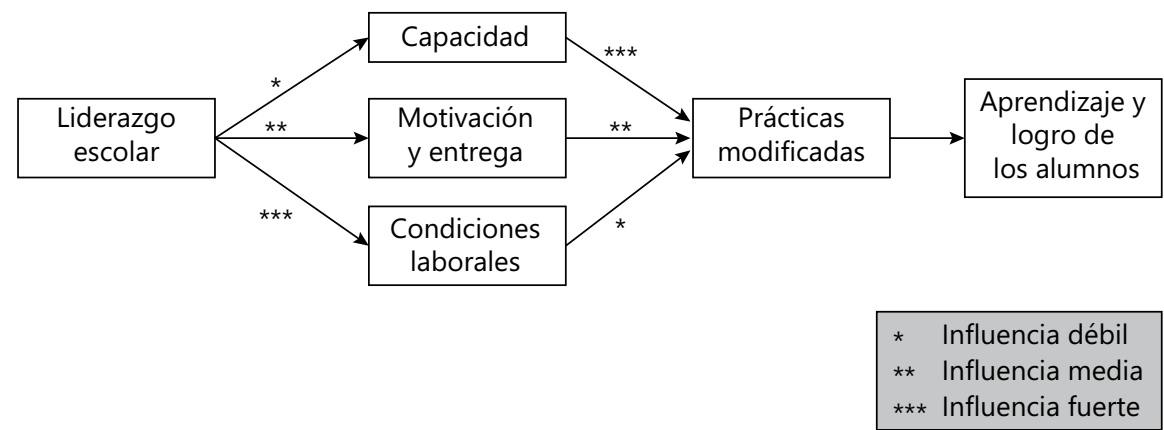

Fuente: Traducción propia de Leithwood et al. (2007, p. 10).

Figura 1. Los efectos de los líderes escolares en las capacidades, motivación, entrega y creencias de los profesores acerca de las condiciones laborales. 
la influencia referida a motivación docente; y la referida a percepción positiva de condiciones laborales.

Sobre el primer punto, el estudio realizado en Chile por Bellei et al. (2003), constata que entre las características de las escuelas efectivas está el desarrollo de las capacidades de los profesores como un factor que no queda a la improvisación ni a las voluntades de los docentes; por el contrario, se cuenta con variados mecanismos para enfrentar este tema y una de las características comunes es que los directores saben aprovechar y potenciar al máximo a sus profesores. Bajo ese contexto, las políticas de mejoramiento educativo que no incorporen estrategias para potenciar este rol en los directivos, evidentemente tendrán serias limitaciones en su viabilidad y eficacia.

Sobre la influencia motivacional, Razcynski y Muñoz (2005) señalan que los buenos resultados educativos en escuelas en sectores de pobreza muestran que los directores son "altamente motivadores, que constantemente instan a los profesores a trabajar duro en pos de los objetivos de la escuela; en este sentido, son directores que apuestan y actúan para lograr un mayor involucramiento de sus docentes, a través refuerzos positivos y de un reconocimiento permanente de su trabajo" (p. 45).

Leithwood (2009) señala que una de las labores claves de un director es manejar las emociones en la escuela, ya que las condiciones laborales de los profesores afectan su motivación, lo que influye directamente en las prácticas en el aula. Muchas de las cosas que pasan en las escuelas dependen de cómo los profesores se sienten; si perciben apoyo y se comprometen con la escuela, habría efectos positivos en su trabajo en el aula y en los logros de sus estudiantes. Es por esto que la motivación y control de emociones de los profesores debería ser parte del entrenamiento que reciben los directores.

La experiencia agregada de los sistemas de mayor desarrollo educativo (Barber; Mourshed, 2008) nos confirma que para lograr esta motivación en los docentes se requiere de un cambio profundo, que va más allá de los incentivos materiales, pues las altas expectativas de logro en los docentes se asocian a la percepción de un objetivo común y a la confianza en la capacidad colectiva de lograr un cambio en el aprendizaje de sus estudiantes.

Es evidente lo gravitante que se torna el que una política educativa incorpore estrategias orientadas a dotar a los directivos escolares de las competencias necesarias para influir en la motivación, compromiso y adhesión de los docentes 
a un proyecto común de escuela, de tal forma que la traducción de este ethos se verifique en la mejora sistemática de la práctica pedagógica y en los esfuerzos por aportar una formación pertinente para el desarrollo de los estudiantes.

Por último, sobre el aporte del liderazgo en la percepción que los docentes tienen de sus condiciones laborales, es posible observar en investigaciones realizadas en Estados Unidos (NEA, 2008) que los docentes asocian una buena percepción de dichas condiciones a factores vinculados a: la organización de la escuela, la colegialidad de sus relaciones profesionales, la confianza y cercanía de los directivos; en definitiva, elementos que están dentro de la esfera de actuación de los líderes. La Figura 2 presenta algunos resultados de este estudio.

Como se observa, el ámbito de liderazgo es aquel que posee mayor importancia para la permanencia de los docentes en sus escuelas, y como se ha visto, los demás aspectos son áreas de directa incidencia de una buena gestión.

En la misma línea, la investigación realizada por Buckley, Schneider \& Shang (2004), aborda el tema de la desmotivación de los profesores, tanto nuevos como con experiencia, y señala que el $25,0 \%$ de los profesores que se inician en los distintos estados de Estados Unidos abandonan la profesión en los primeros cuatro años de trabajo. También el estudio identifica algunos factores que están

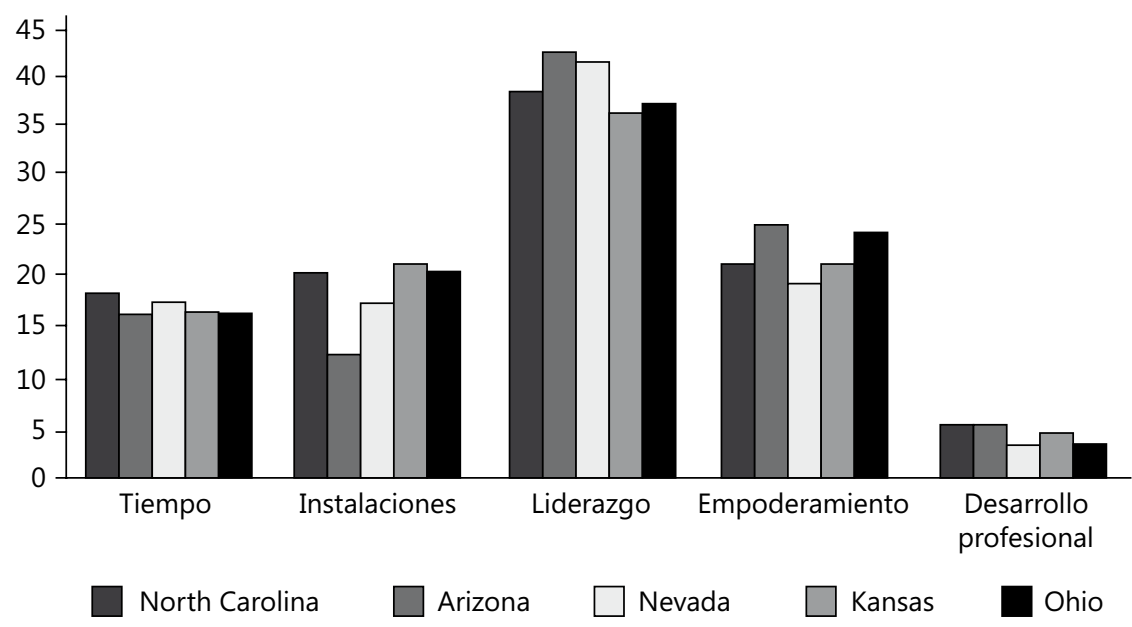

Fuente: Traducido por los autores de NEA (2008, p. 3).

Figura 2. Condiciones laborales que más afectan la motivación de los profesores por permanecer en la escuela. 
directamente asociados con la motivación para permanecer en las escuelas y el ambiente laboral, señalando en general los siguientes aspectos:

- Remuneración versus condiciones laborales: los sueldos son una causa importante del retiro de los profesores del ejercicio de su profesión. Sin embargo, esta investigación revela que buenas condiciones laborales pueden superar los temas de bajos sueldos.

- Gestión escolar versus ambiente laboral: los factores organizacionales de la escuela contribuyen al compromiso que los profesores despliegan hacia su institución. La evidencia muestra que si la gestión escolar libera o disminuye la carga de las obligaciones no relacionadas con la enseñanza, esto afecta positivamente el compromiso de los profesores, especialmente los nuevos.

Johnson (2006) recopila investigaciones realizadas por distintas instituciones y analiza las condiciones laborales de los profesores y la forma en que estos contextos contribuyen a su deseo de entrar y mantenerse en su rol de educadores, destacando como una de las principales conclusiones que las condiciones laborales de los profesores es uno de los factores responsables de que muchos profesores abandonen la profesión al poco tiempo de ingresar a ella. Otro hallazgo de esta investigación es que reconoce al director como el agente responsable de las condiciones laborales, ya que es quien tiene la autoridad formal en la escuela, quien supervisa el trabajo de los profesores, y quien cumple un rol como de enlace entre la escuela y la comunidad.

En otras palabras, como señala el informe elaborado por Southern Regional Education Board, (GRAY et al., 2007), "después de dos décadas de depender principalmente de los estándares académicos estatales, maestros y pruebas... los que diseñan políticas se dan cuenta ahora de que no es posible que las escuelas muestren mejoras sustanciales sin directores altamente eficaces" (p. 9). Es así como hasta la fecha no hay evidencia que muestre un avance en el rendimiento de escuelas que inicialmente presentaban serias dificultades, sin la intervención de líderes talentosos que contribuyan a revertir esta situación (MARZANO; WATERS; MCNULTY, 2005).

Adicionalmente, Marzano (2003) afirma que el liderazgo juega un rol crítico y "puede ser considerado el aspecto más importante de la reforma escolar efectiva [...] pues ejerce influencia sobre todos los aspectos del modelo de eficacia escolar" (p. 172); así también, es clave distinguir que el liderazgo es fundamental para 
que en la escuela exista la posibilidad de introducir cambios que promuevan la mejora continua (ROBINSON; HOHEPA; LLOYD, 2009).

Así mismo, el trabajo realizado por Horn y Marfán (2010) hace una revisión de un conjunto de estudios sobre liderazgo educativo, dando cuenta del sustento empírico existente para "apoyar la idea de que, en Chile, el liderazgo educativo es un factor capaz de producir cambios en la organización escolar que promuevan la calidad de los aprendizajes" (p. 90).

Para el National College for School Leadership (SHELTON, 2009), la presión que existe por dar respuesta y proporcionar un giro en las escuelas de bajo rendimiento debe considerar que para ello la dotación de líderes escolares efectivos es clave. Nuevamente, los antecedentes de esta investigación apuntan a mostrar que en las escuelas son los profesores los que tienen un efecto inmediato sobre el rendimiento y éxito de los estudiantes, pero hay mayor consenso de que es el director o directora quién está mejor posicionado para asegurar que la enseñanza y el aprendizaje sean efectivos en la escuela.

La evidencia revisada muestra la importancia del liderazgo para producir los quiebres necesarios que modifiquen el rumbo de la escuela, sobre todo en aquellas cuyo historial de bajos resultados y dificultades de gestión ha sido la tónica. Esto plantea un gran desafío para los sistemas educativos en el sentido de contar con una efectiva provisión, mantención y desarrollo de líderes educativos de excelencia en los establecimientos.

En este contexto, la disyuntiva que enfrentan los sistemas educativos es el diseño de políticas que aseguren la presencia de este factor en todas las organizaciones escolares, pues más allá de comprender esta variable desde una óptica de micropolítica escolar, lo relevante es la ventaja que puede ofrecer para los procesos de cambio y mejoramiento sistémico de las escuelas. Es decir, se debe resguardar que las políticas y programas nacionales o subnacionales de educación avancen en la implementación de líneas de acción eficaces para el reclutamiento, selección, inducción, formación, evaluación y desarrollo de líderes directivos en las escuelas y, adicionalmente, se debe incorporar estratégicamente esta variable en las políticas como un factor endógeno y no como un elemento exógeno sobre el cual se interviene en forma aislada, con enfoques heterogéneos y hasta contradictorios, que más bien relativizan su influencia y desarrollo, en vez de fortalecerlo. 
La generación de nuevas políticas y programas de desarrollo educativo debieran incorporar estrategias de fortalecimiento del liderazgo directivo como uno de sus componentes principales, siendo inclusive un factor sobre el cual se pueda articular toda la política, pues en la perspectiva de mayor descentralización y autonomía de los sistemas educativos, las decisiones producidas e implementadas por los propios centros educativos son claves para una mejora sostenible.

En la medida que un país se plantee seriamente esta variable como plataforma de desarrollo de sus políticas educativas, y abandone la quimera de sustentarlas en la generación de castas tecnocráticas que subsisten al alero de la centralización exacerbada, estará potenciando efectivamente la calidad de su educación; prueba de ello es el desarrollo de diversos países que han reconocido las ventajas comparativas de fortalecer los procesos de toma de decisiones, basadas en un buen balance entre autonomía y responsabilización de los organismos locales y las escuelas, en la cual el Estado interviene para regular las relaciones, compensar desigualdades y asegurar equidad, favoreciendo procesos de desarrollo endógeno de territorios y no interviniendo directamente en la ejecución de las iniciativas.

\section{Las políticas de liderazgo escolar en los países de la OCDE}

Pont, Nusche y Moorman (2009), establecen cuatro ámbitos de desarrollo de las políticas educativas, impulsadas en la actualidad en los países de la Organización de Cooperación para el Desarrollo Económico (OCDE), como estrategias para el fortalecimiento del liderazgo escolar. A pesar de la gran heterogeneidad de las experiencias en estos países, y de las dificultades para posicionar en la agenda pública este tema y su consecuente priorización en las políticas públicas, existen ciertas tendencias que se pueden visualizar como buenas prácticas para abordar la problemática, sobre todo para países en desarrollo como Chile, que por lo demás se ha incorporado recientemente a este organismo, y cuyas experiencias pueden ser entendidas como preceptos dignos de adoptar o adaptar.

\subsection{Redefinición de las responsabilidades del liderazgo escolar}

En el ámbito educativo, la autonomía no se traduce automáticamente en mejoras si no hay un mecanismo de apoyo adecuado y una delimitación clara de las responsabilidades de los líderes, definidas a través de una comprensión de las prácticas que mejoran el aprendizaje. Para esto, las políticas educacionales deben apuntar a proporcionar mayores niveles de autonomía con el apoyo técnico, financiero y administrativo necesario. Esto implica redefinir las responsabilidades de los líderes en las escuelas para abordar distintas dimensiones del mejoramiento 
de la enseñanza y los aprendizajes, desarrollando nuevos modelos o marcos de trabajo consensuados con los que dirigen las escuelas para otorgar validez a las iniciativas de desempeño, incentivo y desarrollo de la función directiva.

Los avances en esta materia son diversos; algunos países de la OCDE han definido estándares de buenas prácticas, que han permitido guiar el desarrollo de programas de formación centrados en las funciones prioritarias definidas en los estándares o marcos, y así mismo orientar la selección y evaluación de los directores. Estos marcos se deben desarrollar con la participación y socialización de los propios interesados. En los Países Bajos, por ejemplo, un órgano profesional independiente iniciado por el Ministerio de Educación estableció los Estándares Profesionales para los Líderes Educativos en la Educación Primaria (CHILE, 2005), mientras que en Inglaterra el gobierno asignó la responsabilidad de desarrollar e implantar los Estándares Nacionales para los Directores (CHLE, 2004) a dos agencias públicas no departamentales (la Agencia de Capacitación y Desarrollo, y el Colegio Nacional para el Liderazgo Escolar); por su parte, en Escocia fue el gobierno delegado el responsable del desarrollo y análisis de sus Estándares para la Dirección (INGVARSON et al., 2006).

Pero no solo es necesario que los países tomen acuerdos respecto a los ámbitos de incumbencia del liderazgo directivo en las escuelas, sino también, el desarrollo de alternativas para dotar a esta actividad de las atribuciones y orientaciones necesarias para asegurar el real impacto en las tareas de enseñanza y el consiguiente mejoramiento de los resultados de aprendizaje; es así como dentro de las principales conclusiones y recomendaciones respecto a la redefinición de roles, el estudio de OCDE nos plantea los elementos del Cuadro 1.

La experiencia OCDE al respecto introduce elementos para actualizar las concepciones sobre lo que es dirigir una escuela y los requerimientos que un Estado debe atender para sustentar este rol. En general, se aprecia en ella un claro acento en la concentración de funciones referidas al seguimiento del proceso de enseñanza-aprendizaje y al desarrollo de condiciones administrativas, financieras y de gestión para darle sustento a esta tarea.

\subsection{La distribución del liderazgo en la organización escolar}

Dependiendo de la complejidad y tamaños de las unidades educativas, pueden existir estructuras de liderazgo y administración que contribuyan a una gestión más efectiva. El apoyo a la gestión del rol directivo, se expresa de diversas formas en los países de la OCDE; en algunos casos se incorpora la figura de director adjunto o director asistente (subdirector o codirector), quien normalmente asume funciones 
Cuadro 1. Nuevos roles para el liderazgo educativo.

\begin{tabular}{|c|c|}
\hline Ámbitos & Características \\
\hline $\begin{array}{l}\text { Animar a los líderes } \\
\text { a apoyar, evaluar y } \\
\text { desarrollar la calidad } \\
\text { docente como } \\
\text { principal tarea de su } \\
\text { gestión }\end{array}$ & $\begin{array}{l}\text { - Es necesario fortalecer la influencia del líder educativo en las } \\
\text { decisiones relacionadas con el curriculum y la enseñanza, relevar su } \\
\text { rol de supervisión y monitoreo permanente del proceso educativo } \\
\text { en todas sus dimensiones, particularmente en el aula a través del } \\
\text { seguimiento y evaluación del desempeño de sus docentes. } \\
\text { - Conducir y hacer posible los apoyos idóneos para superar las } \\
\text { debilidades docentes y para propiciar espacios colaborativos de } \\
\text { desarrollo profesional, que hoy son clave para enfrentar los desafíos } \\
\text { multidisciplinarios que demanda la educación en diversidad. }\end{array}$ \\
\hline $\begin{array}{l}\text { Favorecer y propiciar } \\
\text { la fijación de metas, } \\
\text { la evaluación y la } \\
\text { rendición de cuentas } \\
\text { en los líderes } \\
\text { escolares }\end{array}$ & $\begin{array}{l}\text { - Contar con un marco de desempeño claro y establecido, siendo } \\
\text { necesario fomentar la dinámica de planificación estratégica } \\
\text { y la competencia de diseño e implementación de planes de } \\
\text { mejoramiento en pos de estándares amplios establecidos a escala } \\
\text { nacional o local. } \\
\text { - Desarrollar las capacidades de gestión de la información, para } \\
\text { tomar decisiones de redireccionamiento o ajustes oportunos en } \\
\text { sus estrategias de cambio y mejora. } \\
\text { - Formar equipos de trabajo, con una distribución y delegación de } \\
\text { tareas equilibrada y sobre la base de criterios compartidos. }\end{array}$ \\
\hline $\begin{array}{l}\text { Fortalecer el manejo } \\
\text { y las atribuciones } \\
\text { en materia de } \\
\text { recursos financieros } \\
\text { y humanos }\end{array}$ & $\begin{array}{l}\text { - La autonomía permite en muchos casos ajustar los recursos } \\
\text { financieros y humanos a fines netamente pedagógicos, por lo cual } \\
\text { la inversión educativa mejora su calidad y permite satisfacer de } \\
\text { una forma más expedita demandas de apoyo material y humano } \\
\text { para el proceso de enseñanza. } \\
\text { - Mejorar las habilidades de manejo financiero y contable en los } \\
\text { equipos de dirección escolar. } \\
\text { - Ampliar sus atribuciones en la gestión de los recursos humanos } \\
\text { de la escuela. }\end{array}$ \\
\hline $\begin{array}{l}\text { Ampliar el concepto } \\
\text { de liderazgo en } \\
\text { el contexto de } \\
\text { una escuela a un } \\
\text { liderazgo de carácter } \\
\text { sistémico }\end{array}$ & $\begin{array}{l}\text { - Un enfoque de colaboración y asociativismo es la clave para avanzar } \\
\text { en la solución de las dificultades de la organización educativa. } \\
\text { - Es fundamental contar con espacios e instancias en las cuales los } \\
\text { líderes colaboren y transfieran experiencias de desarrollo, junto con } \\
\text { los procesos de distribución de responsabilidades y aseguramiento } \\
\text { de la continuidad de la conducción en las escuelas. }\end{array}$ \\
\hline
\end{tabular}

Fuente: Elaborado a partir de Pont, Nusche y Moorman (2009).

administrativas; así mismo, los mandos medios escolares están compuestos por una variedad de funciones, que van desde subdirectores, jefes de departamento, gerentes y coordinadores de taller, o maestros con deberes especiales.

La distribución del liderazgo no solo reduce la carga del director posibilitando una función más abordable, sino que también fomenta la capacidad de liderazgo mediante la planificación y administración de las escuelas y la sucesión del 
cargo. Los consejos escolares también desempeñan una función importante para facilitar el liderazgo y la función del director. Los consejos permiten involucrar a la comunidad, por medio de acuerdos de gobernanza pertinentes y equilibrados, que ayuden a mejorar la gestión escolar. El informe OCDE plantea tres ámbitos de acción para el fortalecimiento de la distribución del liderazgo educativo en las organizaciones, cuyas principales características se presentan en el Cuadro 2.

\subsection{Desarrollo de competencias para un liderazgo educativo efectivo}

Existen diversos mecanismos que apuntan a capacitar y profesionalizar la carrera de los directores y líderes educacionales en la experiencia de los distintos países miembros de la OCDE. Estas alternativas se pueden agrupar, en términos generales, en 3 niveles: Formación inicial o preservicio, Formación de inducción, y Formación continua o en servicio.

La Figura 3 muestra cómo se distribuyen estos tres niveles en los 22 países que han sido parte del estudio de la OCDE. La mayoría cuenta con formación inicial

Cuadro 2. Ámbitos y acciones para distribuir el liderazgo.

\begin{tabular}{|c|c|}
\hline Ámbitos & Acciones \\
\hline $\begin{array}{l}\text { Alentar el } \\
\text { liderazgo } \\
\text { distribuido }\end{array}$ & $\begin{array}{l}\text { - Desarrollar equipos de liderazgo y distribuir tareas formalmente } \\
\text { - Desarrollar procesos más informales de distribución del liderazgo, } \\
\text { basados en el conocimiento especializado más que en el puesto } \\
\text { - Alentar la distribución del liderazgo como una manera de reforzar la } \\
\text { planificación de la sucesión y la administración } \\
\text { - Distribuir el liderazgo entre las escuelas para beneficiarse de las economías } \\
\text { de escala, en especial en las escuelas más pequeñas con menos personal }\end{array}$ \\
\hline $\begin{array}{l}\text { Apoyar la } \\
\text { distribución } \\
\text { del liderazgo }\end{array}$ & $\begin{array}{l}\text { - El desarrollo del liderazgo necesita ampliarse a niveles intermedios } \\
\text { medios y líderes potenciales } \\
\text { - Los responsables de política educativa necesitan reflexionar acerca de } \\
\text { las modificaciones de los mecanismos de rendición de cuentas para } \\
\text { ajustarse a las estructuras de liderazgo distribuido } \\
\text { - Debe haber un reconocimiento más amplio de la función de los equipos } \\
\text { de liderazgo en las escuelas }\end{array}$ \\
\hline $\begin{array}{l}\text { Apoyar a } \\
\text { los consejos } \\
\text { escolares }\end{array}$ & $\begin{array}{l}\text { - Asegurar la coherencia entre los objetivos y expectativas del consejo y la } \\
\text { composición del mismo y el apoyo que recibe } \\
\text { - Mejorar los procesos de selección para estimular la representatividad, } \\
\text { alta calidad y candidatos comprometidos con capacidades adecuadas } \\
\text { - Desarrollar estructuras de apoyo para asegurar la participación activa en } \\
\text { los consejos escolares }\end{array}$ \\
\hline
\end{tabular}

Fuente: Elaborado a partir de Pont, Nusche y Moorman (2009). 


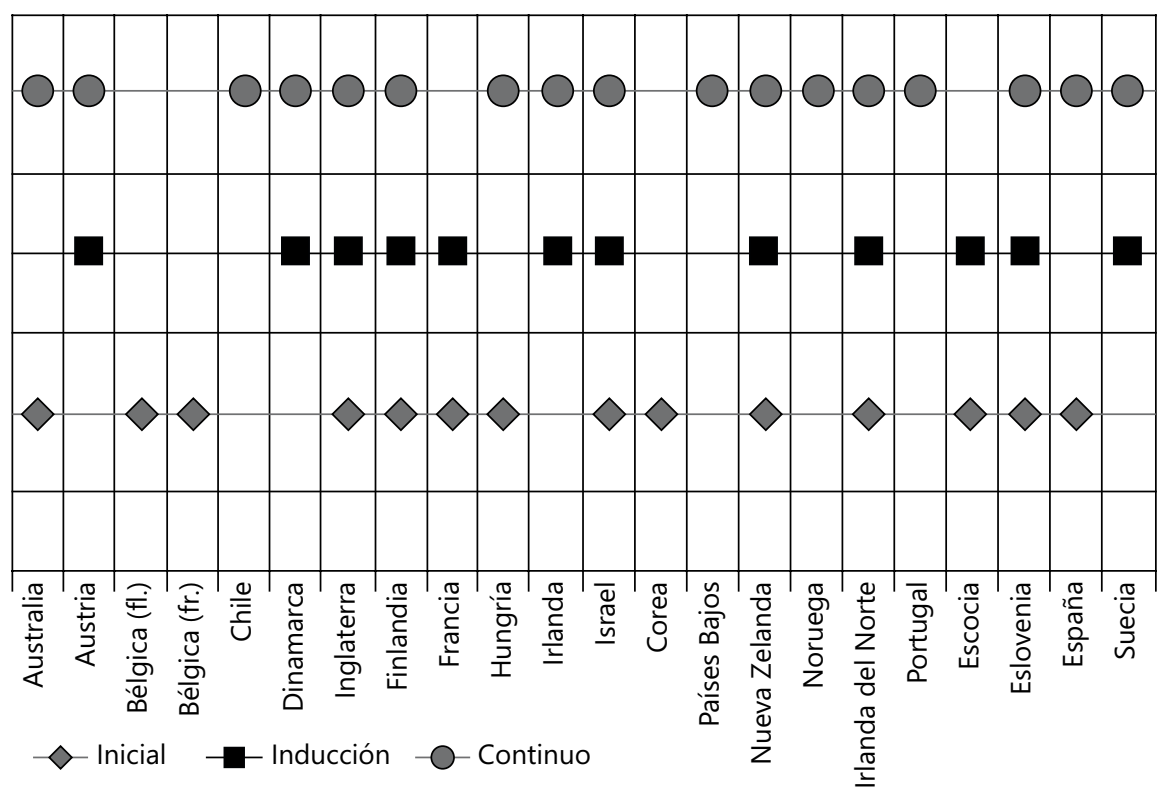

Fuente: Pont, Nusche y Moorman (2009, p. 111).

Figura 3. Programas de Desarrollo de Liderazgo Educativo en Escuela Públicas en países de la OCDE 2006/2007.

(preservicio), es decir, programas de formación y capacitación que se imparten antes de que los directores asuman sus cargos. En todos estos casos, esta formación inicial es obligatoria para asumir el cargo de director. En doce países tienen además programas de inducción para los directores que se están iniciando en el cargo. En estos países, los programas de inducción están generalmente a cargo de los municipios o gobiernos locales (excepto en Austria, en donde la inducción es parte de los requisitos nacionales para ser director). La formación en servicio (continua) para los directores que ya llevan un tiempo en ejercicio, no es tan clara y no hay muchas tendencias comunes en estos países.

En cuanto a la duración de estos programas, esta varía de un país a otro. Se observan programas de certificación muy cortos, de solo algunos meses, hasta diversos programas de postítulo y postgrado. El desarrollo profesional continuo de los directores en ejercicio puede ir desde algunos días hasta provisiones de desarrollo interanual. Los contenidos de los programas pueden ir desde una secuencia orquestada que se ajusta a la evolución de la carrera del director, a programas tipo que se ofrecen en forma de modelo único (one size fits all). 
Los contenidos de los programas de formación también varían desde los que se enfocan y aseguran que los directores se familiaricen y puedan implementar la legislación pertinente al liderazgo escolar, hasta una formación más general y amplia del liderazgo para el cambio. La formación también varía según los roles y responsabilidades de los directores escolares. Por ejemplo, en aquellos países donde los directores (y las escuelas) tienen poca autonomía, los enfoques de la capacitación de directores están dirigidos a desarrollar aspectos prácticos y legales asociados al trabajo. Por otro lado, en aquellos países donde existe mayor grado de autonomía y sistemas de rendición de cuentas (accountability), la capacitación y formación de directores que se observa es más amplia y general, abarcando temas que se asocian a un concepto más global de liderazgo escolar y cambio educativo.

Una característica común en estos países es que la formación y capacitación de directores es un requisito para postular al cargo, junto con ofrecer algunos apoyos financieros públicos. En los países estudiados, los procesos de inducción rara vez se presentan como obligatorios; generalmente quedan al arbitrio de las autoridades locales. Algunos países entregan apoyo para una capacitación más exhaustiva para directores ya en ejercicio. Aunque suele no ser obligatorio, es más frecuente que se asocie a incentivos de sueldos. En algunos casos, los costos de los programas de inducción o capacitación en servicio pueden estar asociados a los presupuestos de las escuelas.

Es común a todos los países de la OCDE que la mayoría de los directores hayan iniciado su experiencia laboral como profesores. Cuando asumen el rol de director, no todos tienen las habilidades y competencias que se necesitan para dirigir pedagógicamente, y generalmente carecen de aptitudes para la gestión en ámbitos financieros y de recursos humanos, así como para trabajar con la escuela y la comunidad; habilidades y competencias que todos reconocen que son fundamentales en la actualidad.

Las principales orientaciones en este ámbito a partir de la experiencia de los países de la OCDE se pueden resumir en:

a) La práctica docente no es garantía de un buen liderazgo directivo, por lo cual los programas de formación deben orientarse a fortalecer la práctica de conducción y dirección escolar.

b) Comprender el desarrollo del liderazgo como un continuo (trayectoria de liderazgo). La experiencia en los países OCDE distingue, al menos: 
- El incentivo para que exista una formación inicial de calidad, en la cual los gobiernos establecen en forma obligatoria la formación en preservicio, o bien estimulan su ocurrencia a través de incentivos, para establecer un cierto "piso" homogéneo de habilidades de liderazgo;

- Implementar programas de inducción que permiten nivelar los conocimientos y habilidades iniciales para el ejercicio de liderazgo;

- Garantizar una formación continua de calidad que responda a las demandas de contenidos y habilidades requeridas por los líderes, para lo cual es fundamental estructurar al menos una porción del programa a partir de sistematizaciones de experiencia y buenas prácticas de liderazgo;

- Por último, la formación debe ser periódica y proporcionada a los equipos para fortalecer no solo sus conocimientos, sino también su cohesión y armonía.

c) Garantizar coherencia entre las distintas ofertas de formación, lo cual implica regular u orientar en algún sentido la gran cantidad de alternativas de formación que caracteriza a algunos países, pero cuya calidad es bastante heterogénea. En los países de mayor desarrollo en el tema, se han constituido organismos nacionales abocados al desarrollo del liderazgo, lo cual ha significado importantes avances.

\subsection{Condiciones para hacer del liderazgo educativo una tarea atractiva}

La experiencia recogida en países de la OCDE sobre este punto, nos presenta un panorama en el que existen dificultades para proveer los cargos de dirección, pues no hay un volumen ni calidad suficiente de candidatos. Este hecho ha sido analizado y se ha descubierto que así como existen factores que propician la decisión de incorporarse a un cargo directivo, que en la mayoría de los casos se refiere a la posibilidad de influir sobre el destino de calidad de las escuelas, o a la posibilidad de desarrollar un proyecto de mejoramiento y transformar a generaciones de estudiantes, también existen factores inhibidores de esta decisión. Algunos de ellos se refieren a: la precariedad y falta de rigor en los procesos de selección; la extensión y desregulación respecto a la jornada de trabajo; el estrés que provoca la responsabilidad del cargo; el abandono de la vida familiar; la baja compensación remunerativa; y la inexistencia de mecanismos de promoción y desarrollo una vez obtenido el cargo. 
En este sentido, la experiencia de estos países señala algunos caminos que han sido desarrollados y que pueden servir de guías para la fijación de políticas eficaces al respecto. La siguiente enumeración recoge las principales estrategias:

a) Profesionalizar la selección de directivos; esto implica avanzar al menos en factores como:

- Ampliar los criterios de elegibilidad para los cargos, incluyendo otros profesionales que no necesariamente sean docentes, facilitando la conformación de equipos interdisciplinario de gestión;

- Planificar la sucesión de los líderes de tal forma que no se interrumpa el desarrollo de la organización con momentos traumáticos como el cambio de dirección. Esto implica identificar con antelación a los posibles aspirantes para poder formarlos y darle continuidad al proceso de desarrollo de la escuela;

- Diseñar sistemas de selección más complejos que incluyan elementos más pertinentes para evaluar a los candidatos, de tal forma que a través de perfiles de competencias, metodologías de simulación, y otras herramientas, se pueda identificar con mayor precisión la existencia de competencias fundamentales para un buen desempeño en el cargo;

- Por último, contar con sistemas de selección dotados de comisiones evaluadoras capacitadas, de tal forma que cuenten con los conocimientos suficientes para utilizar mejores metodologías de evaluación.

b) Propiciar el incremento de remuneraciones en comparación relativa a docentes o profesiones similares. Esto se ha llevado a cabo en algunos países manteniendo una preocupación e influencia desde el sector respecto a cómo se comparan los sueldos de los directivos respecto a otros profesionales con tareas similares en el sector público, de tal forma que se haga patente la brecha que en muchos casos desfavorece a los directores de escuela en comparación con otros directivos.

c) Un tercer elemento de valor en el desarrollo de la profesión directiva ha sido el reconocimiento y fortalecimiento de las organizaciones profesionales como espacios de intercambio de conocimientos, generadores de política educativa y, por tanto, colaboradores en el desarrollo educativo, más que su comprensión como "sindicatos" con los que hay que negociar e intentar obtener mínimos razonables para mantener equilibrios presupuestarios. 
d) Propiciar el desarrollo de una carrera directiva basada en contratos a plazo fijo, susceptibles de ser renovados o descontinuados en mérito del desempeño e incorporar alternativas de continuidad y aprovechamiento de la experticia adquirida en los años de ejercicio para integrar o dirigir organizaciones de carácter intermedio o consultorías en liderazgo para directivos nuevos.

\section{Situación de las políticas de liderazgo directivo escolar en Chile}

La comprensión sobre liderazgo educativo en Chile, en el marco de la política pública reciente, se reduce todavía a su identificación con el concepto de "Dirección Escolar". Tanto en los anuncios ministeriales, como en la normativa actual, la figura que se releva es la de un director o directora al cual se le han incrementado en parte sus atribuciones, haciéndole exigibles mayores responsabilidades, al estilo de un gestor (o gerente) que tiene más dominio sobre elementos críticos de la organización que administra y puede rendir cuenta por su gestión.

Esto es claramente un avance, a pesar del reduccionismo respecto al débil posicionamiento del tema que se observó en décadas pasadas, donde si bien se reconocía que "el liderazgo directivo tiene un impacto significativo sobre la calidad del proceso escolar y el aprendizaje de los estudiantes, y es aún más significativo en las escuelas con bajos resultados..." (CHILE, 2008, p. 8), las iniciativas que se implementaron hasta el año 2010 solo afectaron la duración del cargo y la especificación de elementos básicos sobre el perfil directivo.

Uno de los mayores avances en este período fue la fijación del Marco para la Buena Dirección (MBD) en el año 2005, en el cual se establecen criterios, prácticas o estándares de lo que la política pública considera un buen liderazgo escolar. En este texto se señala lo siguiente respecto a los buenos líderes:

[...] la capacidad de convertirse en líderes de los Proyectos Educativos de sus establecimientos, preocupados por obtener logros de aprendizaje para todos sus estudiantes, logros institucionales y de satisfacción de la comunidad educativa, con capacidad para participar en las definiciones pedagógicas, administrativas y de clima organizacional que se presenten en sus respectivas comunidades de aprendizaje (CHILE, 2005, p. 7).

Continuando en esta línea, y después de un proceso que involucró a diversos actores del sistema educativo, el Ministerio de Educación presentó durante 2015 una 
actualización del Marco para la Buena Dirección y el Liderazgo Escolar (MBDLE) que profundiza en competencias asociadas a la función directiva, y las habilidades requeridas para el ejercicio de un liderazgo escolar contextual y contingente. Este instrumento tiene como propósito ser un referente conceptual que permita proyectar una política educativa que consolide el rol de los directivos escolares, así como también su proceso de autodesarrollo y formación (CHILE, 2015). Si bien esta nueva propuesta muestra avances significativos en la comprensión de la función directiva y el liderazgo escolar, este artículo no profundizará en su análisis por encontrarse recientemente difundido; al mismo tiempo, si bien implica un avance respecto de su predecesor, nada asegura que se modifique su rol, el que hasta la fecha ha sido solo servir como una orientación general que no ha tenido impactos significativos en la política educativa.

Por otra parte, desde el año 2011, con la implementación de la Ley 20.501 (CHILE, 2011) sobre calidad y equidad de la educación, se inician una serie de cambios relevantes, destacando como fundamental la implementación del Sistema de Alta Dirección Pública (SADP), que a partir de 2012 regula la concursabilidad para asumir la función directiva escolar en centros educativos municipales (y también de dirección de departamentos o corporaciones municipales de educación), que va en la perspectiva de aumentar los grados de autonomía de los directores en materia de: gestión de recursos humanos; administración de recursos; definiciones y actuaciones en materia pedagógica; $y$ de obligación de desarrollar autoevaluaciones en virtud de convenios de desempeño y metas de resultado, que incluso podrían significar el cese de funciones directivas anticipadamente.

Un estudio encargado por el Servicio Civil a Grupo Educativo (2015) muestra algunos de los avances del SADP, destacando como fortaleza el funcionamiento general del sistema, pero también plantea desafíos importantes en cuanto al mejoramiento de procesos y las capacidades de algunos actores claves, así como la necesidad de avanzar hacia un sistema de inducción formal, seguimiento y monitoreo efectivo de los compromisos de desempeño de los directivos.

En síntesis, los antecedentes previos muestran que si bien ha existido un avance en las últimas décadas en el ámbito de dirección y liderazgo escolar, podemos reafirmar la evaluación de Weinstein y Hernández Vejar (2014), en relación a que en nuestro país aún existe una baja coherencia interna en cuanto a las políticas educativas para este ámbito, "evidenciándose una falta de alineamiento entre las diversas dimensiones que se han buscado impactar y sin lograr que la mayor definición del quehacer directivo cumpla una función ordenadora más general" (p. 67). 
En las siguientes secciones se hace un acercamiento al esquema planteado por la OCDE el 2009, profundizando en las iniciativas señaladas anteriormente, y en otras, analizando si van en el horizonte de las tendencias más desarrolladas en materia de fortalecimiento del liderazgo educativo, mostrando si estos avances resultan significativos o pueden ser perjudiciales para potenciar esta variable de alta incidencia en la eficacia escolar.

\subsection{Definición de roles y atribuciones para la función directiva}

De acuerdo a las nuevas visiones de la gestión educacional y de los equipos de gestión, los criterios de evaluación han pasado de una visión contable - propia de los años 1980 - a una de responsabilidad sobre los procesos y productos (BALL, 2008); particularmente en el caso chileno, en este ámbito se está transitando hacia la evaluación de resultados y de impacto, dimensión aún germinal.

En efecto, la tendencia de muchos países, especialmente aquellos ligados a la OCDE, es de dotar cada vez de mayores cuotas de autonomía a las escuelas en lo que se refiere a la toma de decisiones curriculares, administrativas y operativas, mientras que se centralizan los estándares y los requerimientos de rendición de cuentas. Por lo tanto, los roles y las responsabilidades de los líderes de las escuelas se han expandido e intensificado en estos países.

Si bien a partir de 2004 la Ley 19.979 (Art. $5^{\circ}, N^{\circ} 1$, CHILE, 2004) ya establecía que la función principal del Director de un establecimiento educacional era dirigir y liderar el Proyecto Educativo Institucional, es desde el año 2011, con la Ley 20.501, que confluyen cambios relevantes orientados a fortalecer el rol de liderazgo directivo, confiriéndole al Director también atribuciones en el ámbito pedagógico, orientadas a dar cumplimiento de sus funciones y asegurar la calidad del trabajo educativo. Adicionalmente, se le confieren, a partir de esta Ley, nuevas atribuciones en materia de gestión de recursos humanos para organizar, supervisar y evaluar el trabajo de los docentes y del personal administrativo. Estos aspectos son significativos para lograr un mayor empoderamiento de los directivos escolares; sin embargo, se mantiene lo que se viene evidenciando desde hace décadas: una débil articulación de los procesos y herramientas de gestión, entre centros educativos y sistemas locales de educación, que limita la sinergia y el potencial de mejoramiento educativo (DONOSO; CANCINO, 2006).

El mismo cuerpo normativo (Ley 20.501, CHLE, 2011) establece que los cargos directivos serán provistos mediante concursos públicos, proceso que será gestionado por el Sistema de Alta Dirección Pública del Servicio Civil de Chile, dejando en manos de los sostenedores (municipios) la convocatoria a dichos concursos, 
que a partir de la definición de un perfil profesional para cada cargo directivo en particular, llevará a cabo los siguientes procesos:

e) Los postulantes deben participar en un proceso de selección, con un etapa inicial que cuenta con el apoyo de expertos en selección de personal (headhunters, psicólogos, etc.), que realizan un proceso de evaluación de antecedentes curriculares y psicolaboral, a partir de antecedentes, entrevistas y aplicación de test psicológicos.

f) Los candidatos preseleccionados pasan a un proceso de entrevista con una Comisión Calificadora compuesta por: el Director del Departamento de Educación o del área educación de las Corporaciones Municipales; un Representante de la Alta Dirección Pública (ADP); y un docente destacado por la evaluación docente o con Asignación Excelencia Pedagógica (AEP) del municipio, que debe ser elegido por sorteo. Esta comisión, después de analizar los antecedentes y entrevistar a los postulantes que han superado la etapa de evaluación psicolaboral, presenta una nómina al Alcalde, quien puede elegir a cualquier candidato de los presentados en dicha nómina, independiente del puntaje específico que obtengan en la evaluación de la comisión calificadora, como también puede dejar desierto el concurso.

g) Posteriormente, el Alcalde firmará un convenio de desempeño con el nuevo director en el que se establecerán las metas y objetivos que deberá cumplir y por las que tiene que rendir cuentas anualmente al sostenedor y al resto de la comunidad. En caso de que las metas no se cumplan, el sostenedor podrá solicitar la renuncia anticipada del director.

Las nuevas atribuciones y asignaciones están asociadas también a exigencias que se deben consignar en el Convenio de Desempeño Directivo, que debe acordarse en un plazo máximo de treinta días contados desde el nombramiento, entre el director del establecimiento y el respectivo sostenedor o representante legal de la Corporación Municipal. Este convenio es público y contiene las metas anuales estratégicas de desempeño del cargo durante el período, los objetivos de resultados a alcanzar por el director anualmente con los correspondientes indicadores, los medios de verificación y supuestos básicos en que se basa el cumplimiento de los mismos, y las consecuencias de su cumplimiento e incumplimiento.

Estos convenios tienen una duración de 5 años contados desde el nombramiento del director del centro educativo, al término de los cuales se deberá efectuar un nuevo concurso, en el que podrá postular el director en ejercicio. Estos concursos 
deben realizarse con la anticipación necesaria para que el cargo no quede vacante. En caso de que sea necesario reemplazar al director del establecimiento, ya sea por su ausencia o por encontrarse vacante el cargo, dicho reemplazo no podrá prolongarse más allá de seis meses desde que dejó de ejercer sus funciones, al cabo de los cuales obligatoriamente deberá llamarse a concurso.

Como se observa, el rol que la política pública le confiere a los directores y directoras de establecimientos educacionales se ha ampliado en los últimos años en el sector municipal en forma considerable, pasando a contener atribuciones y posibilidades de gestión para mejorar la calidad del servicio dentro de un marco de estándares y exigencias que serán evaluadas por organismos especializados de carácter nacional. Cabe señalar que aquellos directores y directoras que ejercen en el sector privado subvencionado, del cual depende la educación de más de un $50 \%$ de los estudiantes, no están afectos a estas disposiciones y, por tanto, las condiciones en las cuales trabajan se establecen sin mayor regulación con sus empleadores; de hecho, no es exigible para este sector concursar los cargos de dirección, y pueden ser nombrados sin contar con los requisitos mínimos, así como tampoco existen mecanismos de control y rendición de cuentas formalmente establecidos.

\subsection{La distribución del liderazgo educativo}

Mediante la promulgación del Estatuto Docente (CHILE, 1997), se establecen las funciones que corresponden a tareas de responsabilidad directiva en el establecimiento educacional, estableciendo roles más allá del cargo de dirección, donde se define la función Técnico-Pedagógica como:

aquellas de carácter profesional de nivel superior que, sobre la base de una formación y experiencia docente específica para cada función se ocupan de campos de apoyo o complemento de la docencia tales como: Orientación educacional y vocacional; supervisión pedagógica; planificación curricular; evaluación del aprendizaje; investigación pedagógica; coordinación de procesos de perfeccionamiento docente; y otras análogas que se determinen, previo informe de los organismos competentes, por Decreto del Ministerio de Educación.

Estos cargos que sirven de apoyo a la función directiva son los que finalmente pasan a conformar el equipo de gestión de un centro escolar, correspondiendo específicamente a: jefe de unidad técnico pedagógica (UTP), orientadores, curriculistas y evaluadores, todos los cuales se vinculan a la función técnico-pedagógica. Tanto la función docente-directiva como la función 
técnico-pedagógica conforman el equipo directivo, y desde la normativa vigente, es en estas funciones formales de un establecimiento educacional en donde los líderes escolares debieran encontrarse.

Por otra parte, uno de los aspectos que destaca en el marco de la buena dirección (CHILE, 2005) es que el liderazgo escolar no puede recaer solamente en la figura del director, sino en la de un equipo de líderes al interior de cada unidad educativa. En general, estos equipos están constituidos por Director, Subdirector, Jefe Técnico, Inspector General, Evaluadores, Curriculistas y otros profesionales de la educación o de apoyo en ámbitos psicosociales, que en su mayoría cumplen funciones docente-directivas y técnico-pedagógicas; sin embargo, debido a la naturaleza de este marco de acción como texto de carácter prescriptivo, lo señalado no establece más que la deseabilidad respecto del comportamiento y desempeños esperados por estos actores, y no compromete formalmente al director y su equipo en estas tareas y responsabilidades.

Finalmente, a partir de la Ley 20.501 (Art. 34, CHILE, 2011), se establece por primera vez la posibilidad de que el Director que es elegido mediante concurso de ADP pueda formar su equipo de trabajo (equipo de gestión), estableciendo que

los profesionales de la educación que cumplan funciones de Subdirector, Inspector General y Jefe Técnico serán de exclusiva confianza del director del establecimiento educacional. Atendidas las necesidades de cada establecimiento educacional, el director podrá optar por no asignar todos los cargos a que hace referencia este inciso. En todo caso, quienes se desempeñen en estas funciones deberán cumplir con los requisitos establecidos en el artículo 24 de esta ley.

Sin embargo, el espectro de posibilidades de conformación se reduce, considerando que el director solo puede nombrar en los cargos mencionados en el párrafo anterior a profesionales que pertenezcan a la dotación docente de la comuna respectiva. Tratándose de profesionales externos a la dotación docente de la comuna, el director del establecimiento educacional requerirá de la aprobación del sostenedor para efectuar sus nombramientos. Lo anterior claramente representa una limitación importante, ya que esto implica la disponibilidad de recursos significativos con los que no cuenta en la actualidad el sector municipal, que es el sector donde tiene implicancia este cuerpo normativo. Por otra parte, tampoco es claro que estas facultades de carácter gerencialista faciliten la eficacia en una organización como la escuela, que posee una dinámica fuertemente comunitaria, basada en elementos socio histórico de relevancia, por lo cual un equipo de 
conducción totalmente ajeno a esa cultura puede generar aislamiento y bandos que entorpezcan la conducción más que potenciarla.

\subsection{Desarrollo de competencias para el liderazgo directivo}

Las competencias de gestión de los directivos de instituciones escolares, pueden ser comprendidas como "la capacidad de conectar conocimientos, habilidades, actitudes e identidad profesional que sean relevantes para una situación con las características personales y desplegarlas de forma integral para hacer posible una actuación adecuada en situaciones profesionales específicas" (KRÜGER, 2009, p. 118).

La brecha existente entre Chile y otros países de la OCDE sobre las condiciones de ingreso a los cargos directivos escolares es importante. En todos los demás países de la OCDE existen requisitos, ya sea de formación inicial, de inducción $\mathrm{y} / \mathrm{o}$ de formación continua, $\mathrm{y}$ el requisito de formación preservicio para acceder al cargo directivo es obligatorio y altamente exigente en la mayoría de estos países. En Chile, sin embargo, las exigencias de entrada no solo son mínimas sino que apuntan solo al sector municipal. En la práctica, en cerca de la mitad de las escuelas (sector subvencionado), el acceso a los cargos directivos está básicamente regulado por criterios de selección particulares y propios de cada institución.

A diferencia de otros países de la OCDE en Chile no existe una oferta de programas de capacitación y/o postgrado diversificada en función de las distintas etapas de la formación profesional (inicial, inducción y de formación continua o en servicio), de las competencias o niveles de complejidad de las funciones o tareas, o de los niveles de experiencia o contextos en que se desenvuelven los profesionales de la educación que están en ejercicio. En contraposición, la oferta de programas se encuentra ampliamente desarrollada en materia de formación continua, los que son diseñados fundamentalmente en términos de los proyectos formativos de cada institución. Los programas existentes en ningún caso son programas de formación inicial o de inducción, pero tampoco son programas que hayan avanzado significadamente en la incorporación de estrategias metodológicas para la formación de competencias para el desarrollo profesional de directivos escolares.

Para Weinstein y Hernández Vejar (2014), "la variada oferta formativa es principalmente otorgada por múltiples universidades e instituciones de educación superior, pero carece de suficiente regulación pública en su calidad y no se encuentra explícitamente alineada al marco de actuación definido para los directivos" (p. 64).

En Chile los únicos programas de inducción se desarrollaron en 2008 y 2009 como una iniciativa piloto, que aún no ha sido probada. A diferencia de los programas 
de formación continua, los programas de inducción fueron diseñados por el Centro de Perfeccionamiento, Experimentación e Investigaciones Pedagógicas ${ }^{1}$ (Cpeip) y la Fundación Chile, con los que se buscó efectivamente responder a las necesidades de los nuevos directores.

Por otra parte, en Chile no hay obligatoriedad de formación inicial como tampoco de capacitación para los directores de escuela, sea esta de inducción o continua, debido a que el Ministerio de Educación no tiene facultad para exigir a las universidades $\mathrm{u}$ otras instituciones que sigan un plan de estudios determinado o que regulen sus condiciones de ingreso en los programas; mucho menos, que modifiquen sus prácticas metodológicas. No obstante, tampoco se han aplicado en forma correcta los incentivos para generar una red de organismos formadores, pues se ha privilegiado a unas pocas instituciones, generalmente radicadas en el área metropolitana, para impulsar programas con recursos del Estado y la oferta a nivel de regiones es escasa, de débil calidad o inexistente. No existe en Chile una política de Estado o planificación estratégica para abordar el tema de la formación de líderes educativos; este aspecto está, más bien, sometido a la decisión de las autoridades de turno.

En otro ámbito, tampoco existe evidencia documentada de programas orientados a promover el desarrollo de redes de directores que les permita un campo de perfeccionamiento entre pares, más allá de la academia (mejores prácticas). De manera análoga, los programas de formación no consideran trabajos de mentoría o coaching como tampoco se explotan de manera importante los elementos contextuales del trabajo del director, aspectos presentes en los programas de formación de inducción y continua de los países de la OCDE.

Cibulka (2009) refuerza la importancia de la investigación enfatizando que los programas de formación que busquen dar un buen entrenamiento y se orienten hacia las necesidades críticas de los directores en el sistema escolar deben basarse en los resultados de las prácticas y técnicas de entrenamiento efectivas. Al mismo tiempo, es importante considerar que la formulación de estándares válidos y confiables debe sustentase en los resultados de investigaciones (INVARGSON et al., 2006).

La última experiencia relevante en este ámbito es el programa de formación de Directores de Excelencia que se inició el año 2011, con el objetivo de fortalecer las capacidades de liderazgo directivo centrado en lo pedagógico, y que durante su primera fase de implementación hasta el año 2013 había incorporado a cerca de 2500 directores en ejercicio y docentes con proyección de ejercer el cargo de

Organismo del Ministerio de Educación que diseña, implementa y evalúa la política nacional de desarrollo profesional de docentes, equipos directivos y asistentes de la educación (www.cpeip.cl). 
director de centro a programas de formación en modalidad de cursos, pasantías, diplomados y magíster, ejecutados por instituciones universitarias y organismos de capacitación acreditados ante el Cpeip, cuyo diseño presentó orientaciones similares a programas internacionales de formación en liderazgo educativo (CAMPOS et al., 2014).

\subsection{Condiciones para el ejercicio de cargos directivos}

En Chile el cargo de director no resulta ser una actividad atractiva, al menos dentro del sector municipal, por la falta de autonomía, la sobrecarga de exigencias administrativas, las bajas remuneraciones en términos relativos respecto al sueldo de los docentes de aula y otros cargos directivos del sector público, la multiplicidad de dimensiones de la cuales se debe responsabilizar con un escaso, o por el inexistente equipo de trabajo (DONOSO et al., 2012). Estas son algunas de las diversas variables que explican la limitada participación de candidatos que cumplan con requisitos mínimos en los procesos de concurso a estos cargos. Sin ir más lejos se ha constatado que en una buena parte de los concursos para proveer los cargos de directores, son los mismos que ya estaban en este rol los que vuelven a ser reelegidos o bien se desplazan a otra escuela de la comuna $u$ otra comuna, por ocupar una vacante.

Esto también se explica por qué la Ley 20.006 (CHILE, 2006) que exigió la provisión de cargos para el sector municipal a través de concursos, no eliminó la posibilidad de que los directores que no fueran seleccionados para un nuevo período o no concursaran, tuviesen que abandonar el sistema escolar. Por tanto, la carga presupuestaria que supone no elegir a un director y mantenerlo como una planta paralela desinhibe a los municipios para procurar su renovación.

La información respecto a remuneraciones nos indica que un director en el sistema subvencionado en Chile recibe como promedio cerca de 1,3 PIB per capita, lo cual en términos comparativos con los países de OCDE nos ubica a un punto por bajo del promedio de remuneraciones de esas naciones (2,3 PIB per capita). Si la comparación se efectúa al interior del sistema escolar es posible encontrar casos en los cuales algunos docentes de aula reciben entre $10,0 \%$ a $15,0 \%$ más de sueldo que el director de su propia escuela y, en general, docentes que reciben asignaciones por desempeño a veces igualan el sueldo de los directivos, o estos solo los superan cuando corresponden a directivos que tienen más de 10 bienios de experiencia, aun cuando la diferencia no sobrepasa un sueldo mínimo (UNIVERSIDAD ALBERTO HURTADO, 2011). 
No obstante las últimas modificaciones al Estatuto Docente incorporadas a través de la ley 20.501 (CHILE, 2011), los nuevos directores deberían acceder a mejores sueldos, siendo coherentes con la mayor responsabilidad y el liderazgo que deben ejercer en el establecimiento educacional, pero aun de manera insuficiente. Es por ello que se aumenta la asignación directiva según la matrícula total y el grado de concentración de estudiantes prioritarios del establecimiento en que se desempeña, como se muestra en la Tabla 1.

Para los directores de establecimientos con matrícula inferior a 150 estudiantes rige el margen anterior de 25\% de la Remuneración Básica Mínima Nacional el cual solo se incrementa hasta un 37,5\% en establecimientos que van desde los 150 a los 399 estudiantes. Tratándose de establecimientos educacionales con una matrícula total entre 400 y 799 estudiantes, la asignación mínima para su director será de un $37,5 \%$ de la RBMN y de $75 \%$ si su matrícula es de 800 a 1.199 estudiantes. Por último, si la matrícula oscila en los 1.200 o más estudiantes, será de $100 \%$ de la RBMN. Estas asignaciones se calcularán anualmente considerando el promedio de la asistencia media del año anterior al que se reciba el beneficio.

Adicionalmente, se otorga un segundo incremento en virtud de la concentración de estudiantes prioritarios en cada establecimiento, lo cual permite duplicar en algunos casos la asignación de responsabilidad de los directores. Este cálculo se realiza conforme a la cantidad de estudiantes prioritarios que al superar el $60 \%$ permite que en un establecimiento de 400 y hasta 799 estudiantes se incremente en un $37,5 \%$, constituyendo un $75 \%$ de asignación. Para aquellos de 800 a 1.199 estudiantes, se incrementa en un $75 \%$ constituyendo un $150 \%$ de la RBMN, y si tuviese una matrícula total de 1.200 o más estudiantes, se adiciona un $100 \%$, permitiendo constituir un $200 \%$ de la RBMN de asignación. Un cuadro explicativo de estas nuevas asignaciones es el que se muestra en la Tabla 2.

Tabla 1. Ingresos promedios en dólares de directores por sexo y dependencia - año 2010.

\begin{tabular}{lcccc}
\hline \multirow{2}{*}{ Sexo } & \multicolumn{2}{c}{ Dependencia administrativa establecimientos } & Media de \\
\cline { 2 - 4 } & Municipal & $\begin{array}{c}\text { Particular } \\
\text { subvencionado }\end{array}$ & $\begin{array}{c}\text { Particular } \\
\text { pagado }\end{array}$ & $\begin{array}{c}\text { ingresos } \\
\text { Hombre }\end{array}$ \\
Mujer & $\$ 2.201$ & $\$ 2.191$ & $\$ 3.203$ & $\$ 2.221$ \\
Promedio & $\$ 2.107$ & $\$ 1.761$ & $\$ 2.477$ & $\$ 1.925$ \\
\hline
\end{tabular}

Fuente: Adaptado de Universidad Alberto Hurtado (2011, p. 7) considerando valor dólar del 30 de diciembre de 2010. 
Tabla 2. Asignaciones especiales para cargos directivos según tramo de matrícula.

\begin{tabular}{|c|c|c|c|c|c|c|c|c|}
\hline Cargo & $\begin{array}{l}\text { Matrícula } \\
\text { hasta } 150\end{array}$ & $\begin{array}{l}<60 \% \\
\text { Alum. } \\
\text { PRT }\end{array}$ & $\begin{array}{l}\text { Matrícula } \\
\text { entre } \\
400 \text { y } 799\end{array}$ & $\begin{array}{c}<60 \% \\
\text { Alum. } \\
\text { PRT }\end{array}$ & $\begin{array}{c}\text { Matrícula } \\
\text { entre } 800 \\
\text { y } 1.199\end{array}$ & $\begin{array}{c}<60 \% \\
\text { Alum. } \\
\text { PRT }\end{array}$ & $\begin{array}{c}\text { Matrícula } \\
\text { superior } \\
\text { a } 1200\end{array}$ & $\begin{array}{c}<60 \% \\
\text { Alum. } \\
\text { PRT }\end{array}$ \\
\hline \multirow{2}{*}{ Director } & \multirow{2}{*}{$25,0 \%$} & \multirow{2}{*}{$\begin{array}{l}\text { No } \\
\text { aplica }\end{array}$} & $37,5 \%$ & $37,5 \%$ & $75,0 \%$ & $75,0 \%$ & $100 \%$ & $100 \%$ \\
\hline & & & \multicolumn{2}{|c|}{$75,0 \%$ RBMN } & \multicolumn{2}{|c|}{$150 \%$ RBMN } & \multicolumn{2}{|c|}{$200 \%$ RBMN } \\
\hline $\begin{array}{l}\text { Otros } \\
\text { directivos } \\
\text { y UTP }\end{array}$ & $20,0 \%$ & $\begin{array}{c}\text { No } \\
\text { aplica }\end{array}$ & No aplica & $\begin{array}{c}\text { No } \\
\text { aplica }\end{array}$ & No aplica & $\begin{array}{c}\text { No } \\
\text { aplica }\end{array}$ & No aplica & $\begin{array}{c}\text { No } \\
\text { aplica }\end{array}$ \\
\hline $\begin{array}{l}\text { Otro de } \\
\text { UTP }\end{array}$ & $15,0 \%$ & $\begin{array}{c}\text { No } \\
\text { aplica }\end{array}$ & No aplica & $\begin{array}{c}\text { No } \\
\text { aplica }\end{array}$ & No aplica & $\begin{array}{c}\text { No } \\
\text { aplica }\end{array}$ & No aplica & $\begin{array}{c}\text { No } \\
\text { aplica }\end{array}$ \\
\hline
\end{tabular}

Fuente: Elaboración propia a partir de Ley 20.501 (CHILE, 2011).

\section{Conclusiones: desafíos para la implementación de políticas efectivas de liderazgo escolar en Chile}

En la última década el tema de gestión escolar y liderazgo educativo ha ocupado de manera significativa la agenda educativa en Chile. Es impensable hablar de mejoramiento de la educación sin referirse al rol de los equipos directivos en este esfuerzo, fruto de lo cual en la primera mitad de este decenio el país dio importantes pasos para regular esta función, otorgarle mayores atribuciones a los directivos y mejorar las condiciones de operación y rendición de cuentas en sus establecimientos. Diversas leyes (Ley 19.933 (CHILE, 2004), 20.006 (CHILE, 2005), 19.979 (CHILE, 2004), 20.248 (CHILE, 2008), 20.158 (CHILE, 2006) y 20.501 (CHILE, 2011), entre otras) han incorporado elementos para: estructurar su rol con mayor claridad; proporcionar atribuciones acordes con los requerimientos de esta función; mejorar la provisión de recursos y las exigencias de planificación estratégica y operativa de los establecimientos; renovar y evaluar los cargos de directores; y percibir incentivos asociados a un buen desempeño de los equipos de dirección. Es decir, un conjunto de normativas que podrían facilitar el empoderamiento de directivos y equipos de conducción escolar respecto al aporte que deben hacer a sus escuelas.

Lo paradójico del tema es que la sensación ambiental sobre el despliegue de esta función refleja precisamente lo contrario: que los directivos carecen de autonomía y reales atribuciones para hacer más efectiva su tarea. No obstante, si valoramos el significativo cuerpo de normativas que hoy se encuentran en plena vigencia para fortalecer el trabajo de los directivos, pareciera que las dificultades que 
enfrentamos para potenciar este rol tienen que ver con otros factores. Por una parte, está, sin duda, la débil institucionalidad que caracteriza a los sistemas de gestión local y comunal de educación, en los cuales muchas veces este marco de normativas no es aprovechada de buena forma; por ejemplo, solo un número reducido de comunas ha otorgado facultades delegadas a sus directivos, situación que había sido consignada en la modificación a la Ley 19.979 del año 2004 (CHILE, 2004). Por otra parte, se puede mencionar la inexistencia de procesos de evaluación de desempeño en el sector municipal, situación que también fue incluida en la citada normativa y que hoy, con la nueva modalidad de concursos y convenios de desempeño, debería fortalecerse.

En definitiva, pareciera ser que en la actual etapa una medida relevante sería implementar los mecanismos pertinentes para que la normativa vigente se aplique, es decir, más que invertir tiempo en el diseño de nuevas normativas, lo aconsejable sería avanzar en las siguientes líneas en el corto plazo:

a) Continuar con los avances y mejoras en el Sistema de Alta Dirección Pública, que permitan: i) fortalecer los procesos de selección de director en el sector público, incrementando las capacidades técnicas de los actores y los mecanismos de monitoreo y control de los procesos; ii) superar aspectos de su implementación que limitan la eficacia del sistema, como son la posibilidad de nombrar en el cargo a cualquier candidato de la nómina final, evitando la posibilidad de decretar desiertos los concursos, y crear las condiciones reales para que el director entrante pueda ejercer sus atribuciones para la conformación de equipos de gestión; y, iii) desarrollar procesos formales de inducción y programas de formación vinculantes a las evaluaciones psicolaborales levantadas durante el proceso de selección, para fortalecer las competencias de dirección y de liderazgo del nuevo directivo.

b) Introducir mejoras en la legislación actual que permita ampliar la exigencia de las normativas (Ley 20.501 (CHILE, 2011) y SADP) al sector particular subvencionado, en el cual la relación de subordinación de los directores a sus empleadores no tiene contrapeso y carece de canales formales para evaluar su desempeño y facilitar su gestión.

c) Considerando la contundente evidencia -internacional y nacional- respecto a la importancia que tiene el que la dirección escolar se concentre en la conducción, seguimiento y retroalimentación del proceso de enseñanza y aprendizaje con los docentes, y la constatación manifiesta de que nuestros directores(as) están lejos de esta actividad. Es necesario reenfocar y fortalecer 
esta dinámica, tanto en las orientaciones y directrices ministeriales, como en los escasos programas de formación que hoy se ejecutan desde el Ministerio de Educación y otras instituciones asociadas. Un gran aporte en este sentido puede significar el hecho de que los procesos de rendición de cuentas que se espera desarrollar para la Subvención Escolar Preferencial, no solo tengan relación con el arqueo de los recursos invertidos, sino también con el logro en la instalación de sistemas de gestión curricular y pedagógica en las escuelas, y con el avance de las metas de aprendizaje establecidas por los establecimientos.

d) Si bien es una buena perspectiva la de delimitar las responsabilidades sobre el mejoramiento de los procesos educativos y los resultados de calidad de los establecimientos, desarrollando marcos y estándares que permitan objetivar los desempeños de distintos actores relacionados, en el ámbito educativo esto no puede atentar contra el valor de la identidad de cada establecimiento educacional. En este sentido, es clave que la estandarización permita a la vez el despliegue de múltiples prácticas de carácter colaborativo, de tal manera que no se entienda que el rol de liderazgo directivo es el de un superhéroe o súper villano, aislado de su comunidad y cuyo rol se limita solo a una serie de procesos administrativos y de supervisión. El perfil extremadamente gerencial de la dirección escolar puede llevar a su aislamiento y hacia prácticas de ostracismo junto a un equipo de confianza que conspira contra el valor de la comunidad; por tanto, es recomendable que las atribuciones sobre el recurso humano permitan la flexibilidad de roles y garanticen condiciones de densidad de los equipos y perfiles profesionales pertinentes con las necesidades de cada establecimiento.

e) Por último, se puede señalar que, en general, la mayor dificultad para avanzar de forma consistente y coherente en una estrategia de fortalecimiento del liderazgo educativo, radica en la desarticulación, descoordinación y fragmentación de la serie de iniciativas que afectan la función directiva, lo cual da cuenta, en algún sentido, de la inexistencia de una política explícita al respecto; se les solicita proactividad, por una parte, pero se les limita la autonomía en decisiones fundamentales; se les pide concentración en los temas docentes, pero se les satura de exigencias administrativas a veces sin sentido; se fomenta su responsabilización por resultados y rendición de cuentas, pero a la vez se les obliga a invertir tiempo y preocupaciones en implementar programas que han sido concebidos fuera de la escuela, etc. Una alternativa que está a la mano y que puede permitirnos despejar el camino se encuentra en los planes de mejoramiento educativo que hoy ejecutan al menos 7.000 escuelas subvencionadas del país. Si toda o gran parte de la política 
educativa se concentrara en garantizar que los establecimientos cuenten con una planificación estratégica y operativa, con metas claras y mecanismos idóneos para su ejecución, con buenos apoyos cuando lo requieran, con financiamiento recurrente para hacer viable su ejecución, con una rendición de cuentas financiera y técnica con consecuencias, y con las condiciones de tiempo y atribuciones necesarias, entonces no habría espacio para el desinterés y la omisión, siendo este el ambiente propicio para el florecimiento de liderazgos fuertes y comprometidos, que puedan conducir a sus comunidades educativas en grandes escuelas líderes del mejoramiento educativo.

Las reformas más exitosas en educación han resultado de un balance correcto entre estándares y metas desafiantes, con buenos apoyos para desarrollar en los actores las capacidades para lograrlos y, todo esto, en un marco de desempeño claro, explícito y con condiciones de institucionalidad suficientes. En Chile hemos avanzado en los estándares y cada vez ponemos metas más desafiantes a nuestras escuelas, nuestros apoyos son precarios, dispersos, limitados en su cobertura y su calidad es heterogénea. Y aun cuando tenemos marcos explícitos de desempeño, la institucionalidad nacional y local es tan precaria, que relativiza toda evaluación y la desplaza hacia el análisis de variables estructurales, o de poca vinculación con la gestión de la escuela.

Todo lo que podamos hacer, entonces, por cerrar las brechas en este u otro tema vinculado con impacto en los aprendizajes, exige de nuestra parte el reconocimiento de que nada se mejora en educación si no se adoptan medidas sistémicas, contextualizadas a los espacios de desarrollo real de las personas, y focalizadas en el fortalecimiento de sus capacidades en paralelo con la determinación de sanciones o exigencias. El desarrollo del liderazgo educativo en el país muestra un claro desbalance en este sentido, y es necesario que se adopten decisiones que están al alcance para superar estas inconsistencias; sin estos arreglos institucionales, ningún programa de formación o modificación contractual podrá garantizar por sí solo el desarrollo de una generación de líderes a la altura del desafío que nuestras escuelas requieren, particularmente aquellas de mayor vulnerabilidad. 


\title{
Politicas educacionais de reforço da liderança diretiva: desafios para o Chile em uma análise comparativa com os países da OCDE
}

\section{Resumo}

Na última década, para muitos países a gestão escolar e a liderança educacional tornaram-se prioridade para as políticas públicas. Vários fatores explicam a importância atribuida a esta função, destacando as expectativas mais elevadas das famílias, exigências de responsabilização por resultados educacionais, novas tendências na prestação de serviços e evidências de pesquisas sobre a influência da qualidade dos processos de gestão e liderança na eficácia da escola. A Organização para a Cooperação e Desenvolvimento Econômico (OCDE) destaca a importância da liderança educacional, analisando a situação atual e as tendências nos países membros, e identificando os fatores-chave para o seu desenvolvimento. O artigo compara as politicas mais recentemente implementadas no Chile, nesta área, contrastando com as experiências dos países da OCDE, onde são sugeridas propostas de desenho para uma política pública sustentável.

Palavras-chave: Direção escolar. Liderança educativa. Políticas de gestão educacional.

\section{Education policies to strengthen directive leadership: challenges for Chile in a comparative analysis with OECD countries}

\begin{abstract}
In the last decade, for many countries the educational leadership and management have become a priority for public policy. Several factors explain the importance assigned to this function, highlighting: higher expectations of families; demands for accountability of educational outcomes; new trends in the provision of services; and evidence of research on the influence of the quality of processes' management and leadership on school effectiveness. The Organization for Economic Cooperation and Development (OECD) highlights the importance of educational leadership, analyzing their current status and trends in member countries, and identifying key factors for its development. The article compares the policies most recently applied in Chile in this area, contrasting experiences of OECD countries. From there, proposals for a sustainable public policy design in the aforementioned framework are suggested.
\end{abstract}

Keywords: School management. Educational leadership. School management policies. 


\section{Referencias}

BALL, S. The education debate. Bristol: The Policy Press, 2008.

BARBER, M.; MOURSHED, M. Cómo hicieron los sistemas educativos con mejor desempeño del mundo para alcanzar sus objetivos. Santiago: CINDE; Washington, DC: Inter-American Dialogue, 2008.

BELLEI, C. et al. Escuelas efectivas en sectores de pobreza: ¿Quién dijo que no se puede?. Chile: Unicef, 2003.

BUCKLEY, J.; SCHNEIDER, M.; SHANG, Y. The effects of school facility quality on teacher retention in urban school districts. Washington, DC: National Clearinghouse for Educational Facilities, 2004. Disponible en: $<\mathrm{http}$ ://www.ncef.org/pubs/teacherretention.pdf $>$. Acceso em: 1 mar 2013.

CAMPOS, F. et al. Formación de directores de excelencia: un mismo objetivo, distintas demandas. Perspectiva Educacional, v. 53, n. 2, p. 91-111, jun. 2014.

CHILE. Ministerio de Educacion. Ley 19.070, de 22 de enero de 1997. Estatuto de los Profesionales de la Educación y de las leyes que la compleentan y modifican(actualización febrero 2011). Disponible en: $<$ http:// www.leychile.cl>. Acceso en: 30 abr. 2013.

CHILE. Ministerio de Educacion. Ley 19.979, de 28 de octubre de 2004. Modifica el régimen de jornada escolar completa diurna y otros cuerpos legales (actualización febrero 2011). Disponible en: <http://www.leychile.cl>. Acceso en: 15 oct. 2013

CHILE. Ministerio de Educación. Ley 19.933, de 12 de febrero 2004. Otorga un mejoramiento especial a los profesionales de la educacion que indica. Disponible en: $<\mathrm{http} / / / \mathrm{bcn} . c l / 1$ uy $48>$. Acceso en: 3 jul. 2015.

CHILE. Ministerio de Educación. Ley 20.006, de 22 de março de 2005. Establece concursabilidad para directores de establecimientos. Disponible en: $<$ http://bcn.cl/1uy48 >. Acceso en: 3 jul. 2015.

CHILE. Ministerio de Educación. Ley 20.158, de 29 de diciembre de 2006. Establece diversos beneficios para profesionales de la educacion y modifica distintos cuerpos legales. Disponible en: <http://bcn.cl/1va28>. Acceso en: 3 jul. 2015.

CHILE. Ministerio de Educacion. Ley 20.248, de 25 de enero de 2008. Estabelece ley de subvención escolar preferencial. Disponible en: $<\mathrm{http}: / /$ www.leychile.cl>. Acceso en: 15 mayo 2013. 
CHILE. Ministerio de Educacion. Ley 20.501, de 8 de febrero de 2011. Calidad y equidad de la educación. Disponible en: $<$ http://www.leychile.cl $>$. Acceso en: 13 jun. 2012.

CHILE. Ministerio de Educacion. Marco de la buena dirección. Santiago: Ministerio de Educación, 2005.

CHILE. Ministerio de Educacion. Marco para la buena dirección y el liderazgo escolar. Santiago: Centro de Perfeccionamiento, Experimentación e Investigaciones Pedagógicas, 2015.

CHILE. Ministerio de Educacion. Mesa de trabajo para carrera docente: síntesis de los avances en la discusión. Santiago: Ministerio de Educación, 2008.

CIBULKA, J. G. Declining support for higher-education leadership preparation programs: an analysis. Peabody Journal of Education: Issues of Leadership, Policy, and Organizations, v. 84, n. 3, p. 453-66, 2009.

DONOSO, S. et al. Análisis crítico de las políticas de formación de directivos escolares en Chile: 1980 -2010. Revista Brasileira de Educação, v. 17, n 49, p. 133-56, jan./abr. 2012. doi:10.1590/S1413-24782012000100008

DONOSO, S.; CANCINO, V. Desafios claves del fortalecimiento de la gestión de los gobiernos subnacionales chilenos en educación. Ensaio: Avaliação e Políticas Públicas em Educação, v. 14, n. 52, p. 311-38, jul./set. 2006. doi:10.1590/S0104-40362006000300003

ELMORE, R. Mejorando la escuela desde la sala de clases. Santiago: Fundación Chile, 2010.

GRAY, C. et al. Schools need good leaders now: state progress in creating a learning-centered school leadership system. Atlanta, Southern Regional Education Board, 2007.

GRUPO EDUCATIVO. Evaluación de la Implementación del Sistema de Selección de Directores en el marco de la Ley $N^{\circ} 20.501$ : percepción de los actores involucrados. Disponible en: $<\mathrm{http}$ :/www.serviciocivil.gob.cl/sites/ default/files/seminario_educacion_adp_grupo_educativo_29_abril_2015.pdf $>$. Acceso en: 25 feb 2016.

HORN, A.; MARFÁN, J. Relación entre liderazgo educativo y desempeño escolar: revisión de la investigación en Chile. Psicoperspectivas, v. 9, n. 2, p. 82-104, 2010. doi:10.5027/psicoperspectivas-Vol9-Issue2-fulltext-116 
INVARGSON, L. et al. Standards for school leadership: a critical review of literature. Acton: Australian Institute for Teaching and School Leadership, 2006.

JOHNSON, S. M. The workplace matters teacher quality, retention, and effectiveness. Washington, DC: National Education Association, 2006.

KRÜGER, M. The Big Five of school leadership competences in the Netherlands. School Leadership \& Management, v. 29, n. 2, p. 109-27, abr. 2009. doi:10.1080/13632430902775418

LEITHWOOD, K. ¿Cómo influye el liderazgo directivo en el aprendizaje de los estudiantes? Una perspectiva basada en la evidencia. 2006. Disponible en: $<$ http://ww2.educarchile.cl/UserFiles/P0001/File/PxL2011_Files/Conferencia Leithwood.pdf>. Acceso en: 23 enero 2016.

LEITHWOOD, K. ¿Cómo liderar nuestras escuelas? Aportes desde la investigación. Santiago de Chile: Salesianos, 2009.

LEITHWOOD, K. et al. Seven strong claims about successful school leadership. Nottingham: National College for School Leadership, 2007.

MARZANO, R. J. What works in schools: translating research into action. Alexandria, ASCD, 2003.

MARZANO, R. J., WATERS, T. \& MCNULTY, B. A. School leadership that works: from research to results. Alexandria: ASCD, 2005.

NATIONAL EDUCATION ASSOCIATION - NEA. Changing roles of school leadership. Washngton, DC: NEA, 2008.

PONT, B.; NUSCHE, D.; MOORMAN, H. Mejorando el liderazgo escolar. Organización para la Cooperación y el Desarrollo Económico, 2008. Vol. 1: Política y práctica.

RACZYNSKI, D.; MUÑOZ, G. Efectividad escolar y cambio educativo: en condiciones de pobreza en Chile. Santiago: Ministerio de Educacion/Unicef, 2005.

ROBINSON, V.; HOHEPA, M.; LLOYD, C. School leadership and student outcomes: Identifying what works and why: best evidence synthesis iteration [BES]. Wellington: Ministry of Education, 2009. 
SHELTON, S. V. Strong leaders strong schools: 2008 state laws. Denver: National Conference of State Legislatures, 2009.

UNIVERSIDAD ALBERTO HURTADO. Faculdad de Educacion. Centro de Investigación y Desarrollo de la Educación - CIDE. VIII Encuesta a actores del sistema educativo 2010. Chile: CIDE, 2011.

WALLACE FOUNDATION. Leadership for learning: making the connections among state, district and school policies and practices. New York, 2006.

Disponible en: $<$ http://www.schoolturnaroundsupport.org/sites/default/files/ resources/Wallace-Perspective-Leadership-for-Learning.pdf $>$. Acesso em: 18 jun. 2014.

WEINSTEIN, J.; HERNÁNDEZ VEJAR, M. Políticas hacia el liderazgo directivo escolar en Chile: Una mirada comparada con otros sistemas escolares de América Latina. Psicoperspectivas, v. 13, n. 3, p. 52-68, oct. 2014. doi:10.5027/psicoperspectivas-Vol13-Issue3-fulltext-468

WEINSTEIN, J.; MUÑOZ, G. ¿Qué sabemos sobre los directores de escuela en Chile?. Chile: Fundación Chile/Ceppe, 2012.

\section{Informações dos autores}

Víctor Cancino Cancino: Doctorando en Dirección y Administración de Empresas, Universidad Politécnica de Cataluña - UPC, Barcelona, España. Magíster en Administración de Empresas, Universidad de Chile. Estudios de Postgrado en Política Educativa en la Universidad Alberto Hurtado. Especialista en Planificación Estratégica e Indicadores de Desempeño - ILPES-CEPAL. Profesor Asociado, Universidad Santo Tomás, Chile. Contato: vcancino@santotomas.cl

Leonardo Vera Monrroy: Doctorando en Política y Gestión Educativa, Universidad de Playa Ancha, Chile. Magíster en Ciencias de la Educación, Universidad René Descartes, Paris V Francia. Asesor del Ministerio de Educación de Chile. Académico universitario. Contato: veraleonardom@gmail.com 